\title{
Molecular evaluation of the great vessels of patients with bicuspid aortic valve disease
}

\author{
Análise molecular dos grandes vasos da base em portadores de valva aórtica bicúspide
}

Mauro PAES LEME', Tirone E. DAVID ${ }^{2}$, Jagdish BUTANY², Diponkar BANERJEE ${ }^{2}$, Eduardo S. BASTOS ${ }^{1}$, Sylvio C. PROVENZANO ${ }^{1}$, Leôncio A. FEITOSA ${ }^{1}$, Henrique MURAD ${ }^{1}$, Monica M. Ferreira MAGNANINI ${ }^{1}$

RBCCV 44205-630

\begin{abstract}
:
Purpose: Bicuspid aortic valve (BAV) is associated with increased prevalence of annulo-aortic ectasia, dissection and ascending aortic aneurysm. This study was undertaken to compare the amount of fibrillin- 1 and elastin in the media of great vessels of patients with bicuspid and tricuspid aortic valve disease. Method: Tissue samples of ascending aorta and pulmonary artery were obtained from 22 patients with bicuspid aortic valve disease (BAV) and 17 patients with tricuspid aortic valve disease (TAV), including 6 normal valves from the transplant program. Indirect immunofluorescence and computerized image analyses were used to quantify fibrillin-1 and elastin of the media of the arteries. The results were expressed as the mean integrated optical density (IOD). Results: In the ascending aorta, the IOD for fibrillin-1 was 15 \pm 8 in the BAV group and $24 \pm 7$ in the TAV group $(p=0.001)$ In the pulmonary artery, the IOD for fibrillin-1 was $18 \pm 10$ in the BAV group and $25 \pm 9$ in the TAV group $(p=0.07)$. In respect to the elastin measurements of the aorta, the specific IOD was $34 \pm 13$ in the BAV group and $29 \pm 14$ in the TAV group. In the pulmonary artery the IOD for elastin was $30 \pm$ 12 in the BAV group and $29 \pm 14$ in the TAV group $(p=0.34)$ Conclusions: Patients with BAV were found to have less
\end{abstract}

Work performed in Toronto University, Toronto Health Care Network together with the Federal University, Rio de Janeiro, Clementino Fraga Filho Teaching Hospital

1 - Federal University, Rio de Janeiro, Rio de Janeiro, Brazil.

2 - Toronto University, Ontario, Canada.

Work partially financed by the Foundation Coordenação de Aperfeiçoamento de Pessoal de Nível Superior - CAPES/PDEE 0548/ 97.9

Correspondence address: Dr. Mauro Paes Leme de Sá. Av. Brig. Trompowsky $\mathrm{s} / \mathrm{n}^{\circ}, 8^{\circ}$ andar. Hospital Universitário Clementino Frag Filho - UFRJ, Serviço de Cirurgia Cardíaca. Ilha do Fundão, Rio de Janeiro. CEP: 21941-590. Phone/fax: (21) 7893-1116. E-mail: maurodesa@uol.com.br fibrillin-1 in the ascending aorta and pulmonary artery than patients with TAV. These findings may explain aortic root dilation and ascending aortic dissection in patients with BAV disease.

Descriptors: Aortic valve, pathology. Aorta, aneurysm, dissection, surgery. Fibrillin. Elastin. Marfan syndrome.

Resumo

Objetivo: A valva aórtica bicúspide (VAB) está associada a maior prevalência de ectasia anulo-aórtica, aneurisma e disseccão da aorta ascendente. Este estudo investigou a quantidade de fibrilina-1 e elastina nos grandes vasos de portadores de VAB.

Método: Amostras de tecidos foram colhidas da aorta ascendente e tronco da artéria pulmonar de 22 portadores de VAB e 16 portadores de valva aórtica tricúspide (VAT) submetidos a cirurgia cardíaca, incluindo seis portadores de valva aórtica normal, provenientes do programa de transplante. Imunofluorescência indireta e análise computadorizada de imagens foram utilizadas para 
quantificação das proteínas na camada média dos vasos, expressas como densidade óptica integrada média (DOI).

Resultados: Na aorta, a DOI específica para fibrilina-1 foi $15 \pm 8$ no grupo bicúspide e $24 \pm 7$ no grupo tricúspide $(p=0,001)$. $\mathrm{Na}$ artéria pulmonar, a DOI específica para fibrilina-1 foi 18 \pm 10 no grupo bicúspide e $25 \pm 9$ no grupo tricúspide $(\mathrm{p}=\mathbf{0 , 0 7})$. A DOI específica para elastina na aorta foi $34 \pm 13$ no grupo A DOI especifica para elastina na aorta foi $34 \pm 13$ no grupo
bicúspide e $36 \pm 19$ no grupo tricúspide $(p=0,31)$. Na artéria pulmonar, a DOI para elastina foi $30 \pm 12$ no grupo bicúspide e $29 \pm 14$ no grupo tricúspide $(p=0,34)$.
Conclusões: Os portadores de VAB apresentaram menor quantidade de fibrilina-1, mas não elastina, na aorta ascendente e artéria pulmonar que os portadores de VAT normal ou doente. Estes achados podem explicar a maior incidência de dilatação e dissecção da aorta ascendente em portadores desta má-formação da valva aórtica.

Descritores: Valva aórtica, patologia. Aorta, aneurisma, dissecção, cirurgia. Fibrilina. Elastina. Síndrome de Marfan.

\section{INTRODUCTION}

The bicuspid aortic valve is associated with a greater prevalence of annulo-aortic ectasia, aneurysm and dissection of the ascending aorta [1-3]. The high incidence of individuals with bad congenital formation of the aortic valve and aortic disease suggests a correlation between the two phenomenons [4]. A previous study demonstrated that the risk of aortic dissection is nine times more common in individuals who have from bicuspid aortic valves than in the general population [5].

Degenerative diseases of the media layer are the most common cause of aneurysms involving the proximal thoracic aorta. Even though the majority of cases have an idiopathic origin, some genetic disorders, such as Marfan's syndrome, are associated to premature degeneration of the media layer of the aorta (Figure 1). Glycoprotein, a component of the microfibrillar system, fibrillin-1 has been associated in the pathogenesis of this serious genetic disorders $[6,7]$. Cystic necrosis of the media layer and elastic fragmentation, are common pathological findings in Marfan's syndrome and have been described in patients with bicuspid aortic valves [8]

Antoine Marfan's description of the first patient with what today is denominated as Marfan's syndrome was published in the Medical Society Bulletin of Paris in 1896. After more than 50 years, it is known that the development and eventual rupture of the ascending aortic aneurysm is the most serious complication to be treated by safeguard the life of patients with this disease, which reduces life expectancy by, on average, one third.

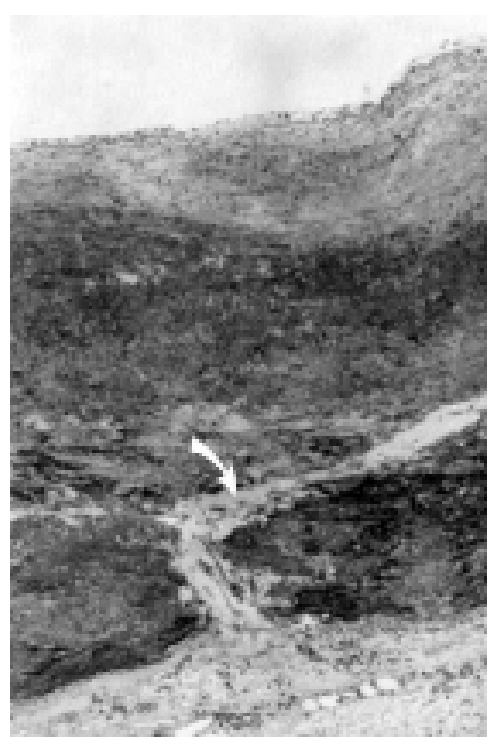

Fig. 1 - Transversal histological section of the ascending artery of a 32-year-old male patient with Marfan's syndrome. Note the complete structural disorganization of the media layer, with intense fragmentation of the elastic tissue and great accumulation of mucopolysaccharides (blue arrow) and cystic fibrosis of the media. Staining method: Movat pentachromic stain. Magnification: $100 \mathrm{x}$. 
MCKUSICK [9], subsequently, elucidated the clinical and hereditary aspects of Marfan's syndrome, characterized by involvement of the eyes, aorta, skeleton and skin. He was also the first to describe the association between the bicuspid presentation of the aortic valve and cystic necrosis in the ascending aortic tunic, as well as the pulmonary artery (Figures 2A, 2B, 3A and 3B).
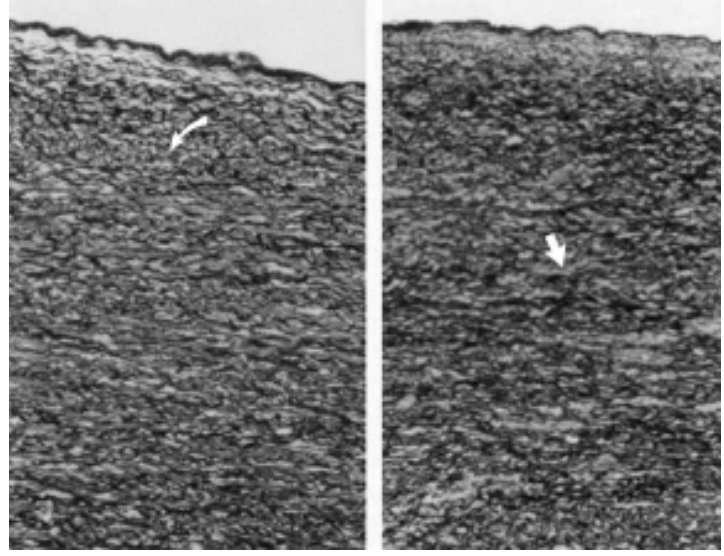

Fig. 2A and 2B - On the left (2A) transversal histological section of the ascending aorta of a 54-year-old male patient with tricuspid aortic valve. Note the small areas with changes in the direction of the smooth muscle cells (arrow) and a slight accumulation of mucopolysaccharides. On the right (2B), transversal histological section of the ascending aorta of a 33-year-old male patient with tricuspid aortic valve and aortic involvement. Note the intense disorganization of the elastic tissue and a great accumulation of mucopolysaccharides (arrow) in all the media layer (cystic necrosis of the media). Staining method: Movat pentachromic stain. Magnification: $100 \mathrm{x}$.

Of the varying proteins that constitute the microfibrils associated with elastin, the most studied is fibrillin-1 due to its association with Marfan's syndrome. However, the relation between fibrillin and other diseases, such as aneurysms and aortic dissections, in patients with bicuspid aortic valves has not been established yet. On the other hand, elastin has been associated to the pathogenesis of supravalvar aortic stenosis [10].

In this study, immunohistochemical, fluorescent microscopic and computerized analysis of images were used to investigate the total amount of fibrillin- 1 and elastin in the media layer of the ascending aorta and the pulmonary artery branch in patients with bicuspid aortic valves. Also the results were compared with measurements obtained from patients with normal and diseased tricuspid aortic valves.

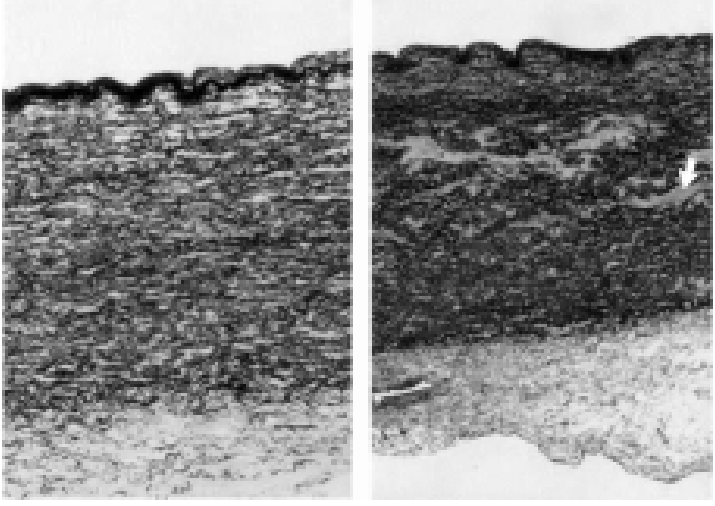

Fig. 3A and 3B - On the left (3A), transversal histological section of the pulmonary artery of a 42 -year-old patient. The elastic tissue, despite being more fragmented than in the ascending aortic artery, maintains the organization of the media layer. The small areas in yellow represent accumulations of collagen. On $t$ he right (3B), transversal histological section of the pulmonary artery of a 40 year-old patient with bicuspid aortic valve, submitted to the operation of Ross. Note the disorganization of the media layer with important alterations in the orientation of the smooth muscle cells and an intense accumulation of mucopolysaccharides in its central area (cystic necrosis of the media layer). Staining method: Movat pentachromic stain. Magnification: $100 \mathrm{x}$.

\section{METHOD}

After obtaining informed written consent from the patients, ascending aortic and pulmonary arterial tissue samples were collected from 39 patients submitted to cardiac surgery. Twenty-two aortic specimens and 16 from the pulmonary artery were obtained from 22 patients with bicuspid aortic valves (BAV group, mean age $42 \pm 12$ years). Seventeen aortic specimens and 12 from pulmonary arteries were also collected from 17 tricuspid aortic valve patients (TAV group, mean age $50 \pm 17$ years). In this latter group, six aortic and six pulmonary arterial samples were obtained from patients with normal tricuspid aortic valves, originating from the transplantation program.

In the BAV group 13 patients presented with aortic stenosis and 9 aortic insufficiency. Only one patient presented with systemic arterial hypertension and none presented with pulmonary arterial hypertension. In the TAV group, 5 patients presented with stenosis and 6 presented with aorta insufficiency. In this group 3 individuals presented with systemic arterial hypertension and none presented with pulmonary arterial hypertension.

\section{Tissue samples}

The tissue samples measuring $10 \times 5 \mathrm{~mm}$, taken approximately $10 \mathrm{~mm}$ distal from the sinotubular junction on 
the anterior face of the aorta and/or pulmonary artery branch were obtained during cardiac surgeries. Subsequently they were preserved in a liquid nitrogen container at minus $70^{\circ} \mathrm{C}$ Sections of 4 to 5 ì were cut using a microtomy.

\section{Technique of partial digestion of the tissue}

Partial enzymatic digestion of the vessels was performed to remove the self-fluorescence of the elastic tissue, before staining for fibrillin- 1 and elastin. This process was necessary because of the intense self-fluorescence of the elastic tissue that can mask the specific immunofluorescence of fibrillin1. For this stage of the preparation, the sections of frozen tissue were fixed in acetone at $4{ }^{\circ} \mathrm{C}$ for 20 minutes and after dried at room temperature before the digestion process was performed. This process was according to the following protocol: Elastase (Worthington Biochemical, Lakewood, $\mathrm{NJ}$, USA) diluted at $0.01 \%$ in $67 \mathrm{nM}$ Tris-HCl buffer at $\mathrm{pH}$ of 8.8 for 20 minutes at room temperature.

\section{Immunofluorescence technique}

After partial digestion, the sections were placed on slides and fixed using acetone for 10 minutes and air-dried. After rinsing with a phosphate buffer solution (PBS), they were treated with human anti-fibrillin-1 mouse monoclonal antibodies (clone 12A5.18, Neomarkers Inc., Union City, California, USA) at a dilution of 1:50 for 1 hour at room temperature. The cuts were then rinsed in phosphate buffer solution and incubated with the secondary antibody for immunofluorescence, IgG from mouse anti-antibody sheep conjugated with $\mathrm{Cy} 3$ (immunofluorescent marker) (Jackson Immunoresearch Lab. Inc., West Grove, PA, USA) at a dilution of 1:100 during 30 minutes. Following this, the slides were rinsed in a phosphate buffer solution and stained for deoxyribonucleic acid (DNA) with 4',6-diamidino-2phenylindole (DAPI) diluted in phosphate buffered saline solution (PBS) $1 \mathrm{ig} / \mathrm{ml}$ (Sigma Chemical Company, St Louis, MI, USA). Only then the material was protected by a cover slide and studied using fluorescent microscopy. The negative controls were stained with omission of the incubation stage using the primary antibody.

For the analysis of elastin, the sections were air dried and fixed with formalin at $4{ }^{\circ} \mathrm{C}$ for ten minutes. After rinsing with a phosphate buffer solution, the sections were stained for elastin (human anti-alpha-elastin rabbit polyclona antibody; Neomarkers Inc., Union City, CA, USA) at a dilution of 1:100 for 1 hour at room temperature. Subsequently, the cuts were rinsed and incubated with antiIgG from mouse antibody sheep conjugated with $\mathrm{Cy} 3$ (Jackson Immunoresearch Lab. Inc., West Grove, PA, USA) at a dilution of 1:20 for 30 minutes. After another rinse with phosphate buffer solution, the sections were covered and stained for DNA with DAPI. The negative controls were obtained omitting the incubation phase with the primary antibody.

\section{Computerized analysis of the Images}

The sections stained for fibrillin-1 and elastin were analyzed using an identification that made it impossible for the observer to recognize the specimen's nature. For this the previously described indirect immunofluorescence technique was employed. Also a computerized image analysis system (MCID; Imaging Research Inc., St Catherine, ON, Canada) coupled to a Xillix MicroImager camera (Xillix, Vancouver, BC, Canada) mounted on a fluorescen microscopy (Olympus BX 50, Olympus America Inc., NY, USA) were employed equipped with filters for different wave lengths. The exposure time of each specimen to obtain a digital image was 884 milliseconds.

The digital images obtained using the Xillix camera were split in minute fragments similar to a mosaic. Each segment is an element or pixel of a figure to be analyzed. A pixel is denominated as whatever area of uniform illumination that forms an image on a video screen.

The size of each fragment is responsible for the degree of resolution of the image. Each of these units is homogeneous in terms of brilliance, which is represented by a numeric value.

This numeric value represents different shades of gray. The different gray tones are expressions of color intensity or brilliance of immunofluorescence. To determine the intensity of brightness or the degree of gray of a specific structure, the computer coupled to the camera, sums all the levels of brightness and divides the total by the number of units or pixels obtaining the Mean Integrated Optical Density (IOD). For specimens marked with fluorescen material, the range of brightness is from 255 or white to zero or black that is without light.

Fluorescent microscopy with quantitative molecular analysi

The detection of both the primary antibodies, antifibrillin-1 and anti-alpha-elastin, were obtained using Cy3 linked to a secondary antibody. This fluorescent substance, $\mathrm{Cy} 3$, was excited by an excitation filter ( 515 to $530 \mathrm{~nm}$ green light) and emissions was detected with a emission filter (540 to $570 \mathrm{~nm}$ ). Utilizing an Uplan FL lens with a magnification of 10x for fibrillin-1 and 20x for elastin, microscopic field of vision, the complete thickness of the vessel was displayed on the computer screen. Regions measuring 200 x $300 \mathrm{ì} \mathrm{m}$ with a magnification of $10 \mathrm{x}$ and $100 \times 150 \mathrm{ì} \mathrm{m}$ with a magnification of $20 \mathrm{x}$ were selected for measurement of the marking made by the primary antibodies. In each specimen, nine different regions distributed between the internal third (proximal to the intima), middle and external (proximal to the adventitia) of the media layer were analyzed. 
For each specimen stained for fibrillin-1, two serial sections were treated using the same methodology, except that, only one was treated with the primary anti-fibrillin-1 antibody. The slide not treated with the primary antibody was the negative control, and was utilized to measure the mean IOD resulting from residual self-fluorescence and whatever non-specific fluorescence resulting from the combination with the secondary antibody conjugated to $\mathrm{Cy} 3$. The quantity of fibrillin- 1 on the treated slide of the primary antibody was measured as the mean IOD which represented the total fluorescence of the specimen, including the non-specific fluorescence and the specific fluorescence of fibrillin-1. The results were recorded as the mean IOD and calculated for the area of the histogram obtained for each studied region (rectangular) (Figure 4).

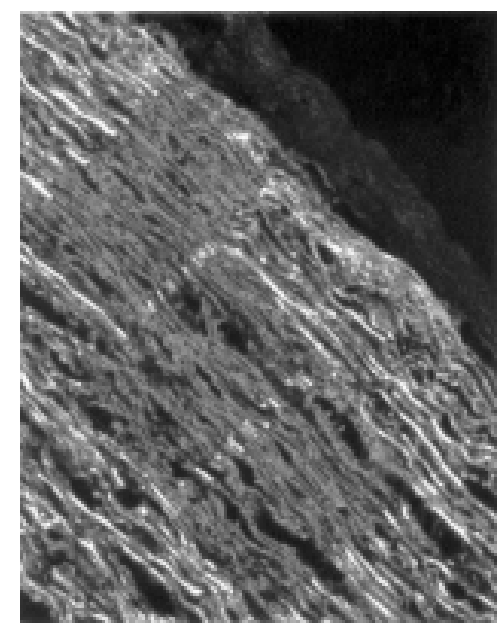

Fig. 4 - Computerized image of transversal histological section of the ascending artery of a patient with tricuspid aortic valve, internal portion of the media tunic of the vessel. Note the proximal areas to the intima layer, where the image analysis system measures the fibrillin-1. Transversal section of the ascending artery, indirect immunofluorescence utilizing monoclonal rat anti-fibrillin- 1 antibody, magnification $20 \mathrm{x}$.

The specific fluorescence of fibrillin-1 (mean of the 9 different analyzed regions) was calculated by subtracting the mean IOD of these slides from their respective negative controls, that is, the total fluorescence was subtracted from the unspecific fluorescence.

The same methodology was used to assess the elastin: for each specimen two serial slides were prepared, one without the primary antibody which was denominated as the negative control. Nine different regions of each specimen with the same distribution as previously described were also studied. Again the mean IOD of the rectangles was calculated through the area of the histogram and stored on the computer. Subsequently the specific quantity of elastin was calculated subtracting the mean IOD of the slide with primary antibody (human anti-alpha-elastin) from its negative control.

After this analysis, the slides were reevaluated utilizing a magnification of $20 \mathrm{x}$ for fibrillin-1 to determine if a difference in magnification could interfere in the results. No difference was evidenced.

\section{Statistical analysis of the molecular evaluation}

Continuous variables were expressed as a mean \pm standard deviation. The differences between the groups were studied by non-matched t-test. Categorical variables were analyzed by Fisher's exact test. The possibility of variations with age was investigated by correlation coefficient and between the different regions in a single specimen by variance analysis for repeated data. A statistical difference was defined when the $\mathrm{p}$-value $<0.05$. Statistical analysis was performed utilizing the Prism Graph Pad software (Graph Pad, San Diego, CA, USA).

\section{RESULTS}

Quantitative analysis of fibrillin- 1 in the ascending aorta

In the BAV group $(\mathrm{n}=21)$ the mean IOD for fibrillin-1 was $61 \pm 8$, with a mean for the negative controls of $47 \pm 6$, giving a specific immunofluorescence of $15 \pm 8$. In the TAV group $(n=17)$ the mean IOD for fibrillin- 1 was $72 \pm 12$, with the mean for a negative controls of $48 \pm 9$ giving a specific immunofluorescence value of $24 \pm 7$. The BAV group revealed a quantity of fibrillin-1 significantly lower in the media layer of the ascending aorta than in the TAV group ( $\mathrm{p}$-value = $0.001)$. However there were no differences in the quantity of fibrillin-1 among the normal or sick TAV individuals ( $\mathrm{p}$-value $=0.30$ ).

The BAV individuals with dilations of ascending aorta aneurysms (diameters of $40 \mathrm{~mm}$ of more), $(\mathrm{n}=10$, mean IOD $13 \pm 9)$ and those without dilations $(n=11$, mean IOD $16 \pm 7$ ) did not present a significant difference in the quantity of fibrillin-1 of the ascending aorta either ( $p$-value $=0.31$ ).

There was no significant difference in the quantity of fibrillin-1 found in the three regions analyzed in each specimen. The mean IOD did not significantly vary among the more internal portions, proximal to the intima, middle and the more external, near the adventitia of the ascending aorta in both of the groups studied.

The correlation coefficient demonstrated that there was no pattern in variations among the quantities of fibrillin-1, that is, the specific immunofluorescence and the age of the patients in both of the groups BAV $(r=0.07)$ and TAV $(\mathrm{r}=-0.52)$. 
Quantitative analysis of the elastin in the ascending aorta

Quantitative analysis of the elastin in the ascending aorta revealed that the BAV group $(n=22)$ gave a mean IOD of $101 \pm 17$, with a mean for the negative controls of $67 \pm 13$ The mean specific immunofluorescence for human antialpha-elastin was $34 \pm 13$. In the TAV group $(n=16)$ the mean IOD was $97 \pm 28$ with a mean of $61 \pm 14$ for the negative controls, giving a specific immunofluorescence of $36 \pm 19$. In spite of the reduced quantity of elastin in the media layer of the aorta of the BAV group, these values did not give a statistically significant difference $(p$-value $=0.70$ ).

The quantity of elastin was not significantly different in the TAV individuals with and without dilation of the ascending aorta $(\mathrm{p}$-value $=0.31)$.

The variance analysis of the repeated data did not demonstrate a significant difference in the elastin distribution among the three different regions of the media layer of the aorta in individuals of the BAV and TAV groups. The correlation coefficient did not evidence a variation pattern between the quantity of elastin of the media layer of the aorta in both the groups, BAV $(r=0.03)$ and TAV $(r=0.24)$.

Among the TAV individuals, there was no significant difference in the quantity of elastin between those with ( $\mathrm{n}=$ 10 , mean IOD $=37 \pm 7)$ and without aortic valve disease $(\mathrm{n}=$ 6 , mean IOD $34 \pm 6$; p-value $=0.72$ ).

Quantitative analysis of fibrillin-1 in the pulmonary artery

The mean IOD for fibrillin-1 in the BAV group $(\mathrm{n}=15)$ was $61 \pm 14$, with a mean for the negative controls of $43 \pm 6$ giving a difference, the specific immunofluorescence of 18 \pm 10 . In the TAV group $(n=12)$, the mean IOD was $71 \pm 10$ with a mean for the negative controls of $46 \pm 6$ giving a specific immunofluorescence for fibrillin- 1 of $25 \pm 9$. Despite of the lower value of fibrillin-1 in the pulmonary artery of the BAV group, this difference was not statistically significant in this sample ( $p$-value $=0.07)$.

There was no difference in the quantity of fibrillinamong the internal, middle and external portions of the pulmonary artery in the BAV and TAV groups. Also no correlation was seen between the age of the patients and the quantity of elastin in the pulmonary arterial specimens for both of the BAV $(r=0.01)$ and TAV $(r=0.09)$ groups.

Quantitative analysis of the elastin in the pulmonary artery Quantitative analysis of elastin revealed that in the pulmonary artery of the BAV group $(\mathrm{n}=14)$, the mean IOD was $90 \pm 24$ with the mean for the negative controls of $61 \pm$ 14 giving a value for specific immunofluorescence of $30 \pm$ 12. In the TAV group $(n=11)$ the mean IOD was $82 \pm 13$ an in the negative controls it was $53 \pm 8$ giving a specific immunofluorescence of $29 \pm 14$. There was no significant difference between the two groups ( $p$-value $=0.34$ ) or among the different regions studied. Again the correlation coefficient did not demonstrate any relation between age and the quantity of elastin in the pulmonary artery of both the BAV $(r=0.015)$ and the TAV $(r=0.091)$ groups.

\section{COMMENTS}

In this investigation, the objective was to quantitatively analyze fibrillin-1, which is involved in the pathogenesis of Marfan's Syndrome, as there are similarities in degenerative histological alterations of the aorta in individuals suffering from this syndrome and alterations in the great vessels of patients with BAV. These alterations include cystic necrosis of the media, elastic fragmentation and alterations in the smooth muscle cells $[4,9,11\}$.

The media layer of the arteries is composed of four components: elastic fibers, collagen fibers, smooth muscle cells and an amorpha substance. It has been shown that the thoracic aorta has proportionally more elastic tissue than the abdominal aorta, which is mainly constituted of smooth muscle cells and collagen [12]. It is believed that the microfibrils associated with the elastin bestow numerous tissues with stretching forces and flexibility, including the great vessels. The developed elastic fibers are mainly composed of elastin associated with microfibrils and elastin in its amorphic format. However, despite of the elastin being in the intima association with microfibrillar structures, these proteins can be found without elastin, suggesting a participation in a broader role in the extracellular matrix of connective tissue [13, 14]. DAVIS [15] suggested that the microfibrils, not associated with elastin, exert a role in the anchoring of the cells and more specifically in the aorta, they are involved in the maintenance of the structural integrity of the endothelium layer of the vascular wall.

This study demonstrated that patients with BAV present with a lower quantity of fibrillin-1 in the ascending aorta and the pulmonary artery than in the normal and sick TAV individuals. However, the total quantity of elastin was similar in both the groups. It is probable that the previously identified histologic alterations [11] reflect a primary fragility of the vessel consequent to a reduction of the fibrillin- 1 in the extracellular matrix.

Previous studies have demonstrated that normal or slightly sick BAV patients present with a greater prevalence of dilation of the aortic root. The hemodynamic alterations alone, produced by a BAV without stenosis or regurgitation, seem to be an insufficient explanation for these findings [1,2]

In this study no significant difference was evidenced in the quantity of fibrillin-1 among the BAV patients with or 
without dilation of the ascending aorta ( $\mathrm{p}$-value $=0.31$ ) This finding suggests that in all the BAV individuals there seem to be a quantitative reduction of fibrillin-1 yet some other factor favors the development of dilations in the ascending aorta.

MILEWICZ et al. [16], studying families of carriers of the Marfan's syndrome, demonstrated different mechanisms responsible for the incongruous production of fibrillin-1: abnormalities in the synthesis, secretion and incorporation in the extracellular matrix. In patients suffering from Marfan's syndrome, in which this latter mechanism was identified, the clinical phenotype ranged from slightly affected, that is, with late aortic involvement after the age of 40 years old, to severe compromise of the phenotype, with early aortic involvement before the age of 20 .

A recent publication about a possible mechanism responsible for the aortic dilation in sufferers of the malformation of the aortic valve concluded that premature apoptosis of the smooth muscle cells of the media layer of the ascending aorta occurs favoring early degeneration of the aortic wall [17].

Some investigators believe that abnormalities in differen phases of cell migration of the neural crest might, either in isolation or in association, be responsible for the occurrence of abnormalities of the aortic valve, the media layer of the ascending aorta and of the vessels of the aortic arch [18 19]. We believe that degenerative alterations described in the pulmonary artery of BAV individuals might be the explanation of the fact that both the aorta and the pulmonary artery structures have the same embryological origin, the conal branch. Additionally, the malformation, frequently only identifiable through an aortic valve with bicuspid morphology, seems to be part of a complex process which also involves the walls of the great vessels. In aortic supravalvar stenosis, ascending aortic stenosis is the predominant anatomical finding, but other arteries are often injured including the pulmonary artery. This observation also reinforces the hypothesis of a malformation that impairs both great vessels.

The fine wall of the pulmonary branch, particularly the fine media layer, reflects the low resistance and pressure of the pulmonary circulation system under normal conditions. In the pulmonary branch of an adult, the quantity of elastic tissue per unit of the media layer surface is only $60 \%$ of that observed in the media layer of the aorta. In this investigation, the quantity of fibrillin- 1 in the pulmonary artery was less in the BAV group; even though statistical significance was not evidenced ( $\mathrm{p}$-value $=0.07$ ), contrary to our expectations. We believe this result may be secondary to a relatively small sample size, thus, it is possible that with a greater number of specimens it would be possible to identify a significant trend in the reduction of fibrillin-1 in the pulmonary samples of the BAV group. Even so, these results might have an impact if we observe the theories that try to explain the phenotypic manifestations of Marfan's syndrome. Our hypothesis is that in a less severe form of this syndrome, the BAV individuals have involvement of the connective tissue, more specifically in the microfibrillar system (Figures 5A and 5B), but also with phenotypic variations.

The analysis of the elastin, both in the aorta and the pulmonary artery, revealed similar values of this protein in the two groups. This fact strengthens the hypothesis of a reduction of fibrillin-1 at the extracellular level.

Knowledge acquired until now about the proteins that make up the microfibrillar system has as its foundation the investigation and the attempt to create experimental models for Marfan's syndrome, as well as the creation of diagnostic tests. In this dominant syndrome, fibrillin-1, the product of a mutant allele, might exert a negative dominant effect over the normal protein product, as multiple molecules of fibrillin1 are gathered in a structure, the microfibril, of which possesses its own regulated functionality in the biological performance of its parts. Presumably, even when some of its subunits present defects, the function of the entire microfibrillar structure would be compromised. Currently, it is believed that a mutation in one allele of fibrillin may cause Marfan's syndrome, if this mutant fibrillin affects in an adverse manner the production, secretion or aggregation in the microfibrillar structure, destabilizing or impeding its adequate functioning [20]. On the contrary to what occurs with Marfan's syndrome, until the present moment, no hypothesis taking into consideration molecular biology and the integrity of the connective tissue has been proposed to explain the greater prevalence of aneurysms or dissections of the aorta in BAV individuals.

In this investigation, the reduced quantity of fibrillin-1, in the media layer of the great vessels of the BAV group can result from a mechanism similar to that proposed for Marfan's syndrome. In this case, even a little significant reduction of this protein in the pulmonary artery would have a pathogenic impact, if the previously described mechanism was applied, which would explain the histological alterations already reported in BAV individuals.

Another theory also proposed to explain Marfan's syndrome, which should not be ignored, is that the structural alteration would simply be caused by a reduction of the normal functioning fibrillin. In this case, the genetic changes would result in an abnormal microfibrillar protein that would not associate with normal fibrillin-1, which in turn would not adversely affect the microfibrils, but could alter the structural integrity of the vessel in a less severe form [20].

The quantity of elastin was similar in both groups suggesting a similar amount of elastic tissue in spite of significant degenerative alterations found in the BAV group 
(cystic necrosis of the media, elastic fragmentation and alterations in the orientation of the smooth muscle cells). A reduction in the amount of fibrillin-1 would have occurred, probably, in the pericellular, resulting in a compromise of the cohesion capacity of the tissues and elastic resistance of the vessel, allowing their early degeneration, which facilitates the development of aneurysms or dissections.

As opposed to other investigations about Marfan's syndrome [21], this did not reveal any difference in the amount of fibrillin-1 or elastin in the internal, middle or external portions of the intima and adventitia layers of the great vessels. However, it evidenced strong staining for both the proteins in the intima and adventitia layers of the vessels, suggesting that they have an important role in response to pulsating waves caused by the cardiac systole in these vessels. However, in the media layer, the distension caused by the pulsating wave does not seem to have a greater effect in the distribution of these proteins.

GODFREY et al. [22] described a reduction in the fluorescence of the fibrillin-1 associated to elastin in relation to age, especially after the first decade of life and insignificant variations after this age. These results are in agreement with results obtained in this study, where the age varied between 24 and 76 years. Utilizing the correlation coefficient, it was not possible to demonstrate a relationship between the quantity of these proteins and the age of the patients.

In the methodology of this study, all comparisons were based on calculations of the area of the histogram, eliminating any possibility of subjective analysis of the visible brightness on the slides. Also the interference caused by the unspecific immunofluorescence not related to the protein molecules in question may have been eliminated in an objective way.

The main limitation of this work is the sample size. Degenerative alterations of the ascending aorta and the pulmonary artery are complex processes. With the techniques currently employed to evaluate the ultrastructural alterations, a prohibitive number of specimens would have to be assessed to understand the true dimension of the problem and all the clinical variables associated with it. Another limitation is that only a small segment of the ascending aorta and the branch of the pulmonary artery of each individual were examined.

Other authors [23-25] believe in the fragility of the aortic wall associated with the presence of BAV, attributed to a significant number of reoperations for dissections or ascending aortic aneurysms in BAV individuals submitted to valve replacements in isolation. Consequently, it is recommended to replace the ascending aorta when its diameter is equal or greater than $45 \mathrm{~mm}$ in diseased BAV replacement surgeries.

Based on these findings and with accumulated clinical experience [23], we believe that the BAV individuals submitted to aortic valve replacement surgery should have the aortic root diameter and ascending aorta carefully assessed. After the diameter, disease of the aortic wall is the most important determinant of the risk of vessel rupture [23]. The ascending aorta with a diameter equal or greater than $45 \mathrm{~mm}$ should be replaced, especially in those patients with a longer life expectancy. Still more importantly, BAV individuals submitted to emergency surgery due to the presence of aneurysms or dissections of the aorta should have their aortic root replaced, without preservation of the coronary sinuses.

In relation to Ross's surgery, we believe that BAV individuals should not be operated on with this technique to replace the aortic root. The inclusion technique or the original subcoronarian implantation technique are the choice procedures, as there are cases described of pulmonary autograft dilation in BAV individuals [26].

Finally, new investigations are necessary to elucidate the role of other proteins in the pathogenesis of aneurysms and dissections of BAV individuals and which mechanisms are involved.

\section{CONCLUSIONS}

1. BAV individuals present with a lower quantity of fibrillin-1 in the ascending aorta and the pulmonary artery when compared with normal or sick TAV individuals.

2. A significant reduction of fibrillin-1 probably occurred in the extracellular matrix, as no reduction of the elastin, a protein associated to fibrillin in the composition of the elastic tissue, was evidenced.

3. The reduction in the main protein of the microfibrillar system, fibrillin-1, was not related to age.

\section{BIBLIOGRAPHIC REFERENCES}

1. Pachulski RT, Weinberg AL, Chan KL. Aortic aneurysm in patients with functionally normal or minimally stenotic bicuspid aortic valve. Am J Cardiol 1991; 67:781-2.

2. Hahn RT, Roman MJ, Mogtader AH, Devereux RB. Association of aortic root dilation with regurgitant, stenotic and functionally normal bicuspid aortic valves. J Am Coll Cardiol 1992; 19:283-8.

3. Gore I. Dissecting aneurysms of the aorta in persons under fourty years of age. Arch Pathol 1953; 55:1-13.

4. Braverman AC. Bicuspid aortic valve and associated aortic wall abnormalities. Curr Opin Cardiol 1996; 11:501-3.

5. Larson EW, Edwards WD. Risk factors for aortic dissection: a necropsy study of 161 cases. Am J Cardiol 1984;53:849-55. 
6. Dietz HC, Ramirez F, Sakai LY. Marfan`s syndrome and other microfibrillar diseases. Adv Hum Genet 1994; 22: 153-86.

7. Hollister DW, Godfrey M, Sakai LY, Pyeritz RE. Imnunohistologic abnormalities of the microfibrillar-fiber system in the Marfan syndrome. N Eng J Med 1990; 323:152-9

8. Lindsay Jr. J. Coarctation of the aorta, bicuspid aortic valve and abnormal ascending aortic wall. Am J Cardiol 1988; 61: 182-4.

9. McKusick VA. Association of congenital bicuspid aortic valve and Erdheim's cystic medial necrosis. Lancet 1972 $1: 1026-7$

10. Ewart AK, Jin W, Atkinson D, Morris CA, Keating MT. Supravalvar aortic stenosis associated with deletion disrupting the elastin gene. J Clin Invest 1994, 93: 1071-7.

11. De Sá M, Moshkovitz Y, Butany J, David TE. Histologic abnormalities of the ascending aorta and pulmonary trunk in patients with bicuspid aortic valve disease: clinica relevance to the Ross procedure. J Thorac Cardiovasc Surg 1999, 118:588-94.

12. Schlatmann TJ, Becker AE. Histologic changes in the normal aging aorta: implications for dissecting aortic aneurysm. Am J Cardiol 1977;39:13-20

13. Jaques A, Serafini-Fracassini A. Morphogenesis of the elastic fiber: an immunoelectronmicroscopy investigation. J Ultrastruct Res 1985, 92:201-10.

14. Cleary EG, Gibson MA. Elastin-associated microfibrils an microfibrillar proteins. Int Rev Connect Tissue Res 1983, 10:197-209.

15. Davis EC. Immunolocalization of microfibril and microfibrilassociated proteins in the subendothelial matrix of the developing mouse aorta. J Cell Sci 1994, 107: 727-36.

16. Milewicz DM, Pyeritz RE, Crawford ES, Byers PH. Marfan syndrome: defective synthesis, secretion, and extracellular matrix formation of fibrillin by cultured dermal fibroblasts. J Clin Invest 1992, 89:79-86.
17. Bonderman D, Gharehbaghi-Schnell E, Wollenek G, Maurer G, Baumgartner H, Lang IM. Mechanisms underlying aortic dilatation in congenital aortic valve malformation. Circulation 1999, 99: 2138-43.

18. Sans-Coma V, Fernandez B, Duran AC, Thiene G, Arque JM, Munoz-Chapuli R et al. Fusion of valve cushions as a key factor in the formation of congenital bicuspid aortic valves in Syrian hamsters. Anat Rec 1996, 244: 490-8.

19. Kappetein AP, Gittenberger-de Groot AC, Zwinderman AH, Rohmer J, Poelmann RE, Huysmans HA. The neural crest as a possible pathogenetic factor in coarctation of the aorta and bicuspid aortic valve. J Thorac Cardiovasc Surg 1991, 102:830-6.

20. Reinhardt DP, Chalberg SC, Sakai LY. The structure and function of fibrillin. Ciba Found Symp 1995; 192: 128-47.

21. Fleischer KJ, Nousari HC, Anhalt GJ, Stone CD, Laschinger JC. Immunohistochemical abnormalities of fibrillin in cardiovascular tissues in Marfan's syndrome. Ann Thorac Surg 1997, 63:1012-7.

22. Godfrey M, Nejezchleb PA, Schaefer GB, Minion DJ, Wang $\mathrm{Y}$, Baxter BT. Elastin and fibrillin mRNA and protein levels in the ontogeny of normal human aorta. Connect Tissue Res 1993, 29:61-9.

23. Ergin MA, Spielvogel D, Apaydin A, Lansman SL, McCullough JN, Galla JD et al Surgical treatment of the dilated ascending aorta: when and how? Ann Thorac Surg 1999, 67:1834-9, discussion 1853-6.

24. Epperlein S, Mohr-Kahaly S, Erbel R, Kearney P, Meyer J. Aorta and aortic valve morphologies predisposing to aortic dissection: an in vivo assessment with transoesophageal echocardiography. Eur Heart J 1994, 15:1520-7.

25. Prenger K, Pieters F, Cheriex E. Aortic dissection after aortic valve replacement: incidence and consequences for strategy. J Card Surg 1994, 9:495-9.

26. David TE, Omran A, Ivanov J, Armstrong S, De Sa MP, Sonnenberg $B$ et al. Dilation of the pulmonary autograft after the Ross procedure. J Thorac Cardiovasc Surg 2000, 119:210-20. 